\title{
Consumer Acceptance of Genetically Modified Foods in the Greater Accra Region of Ghana \\ Eric Worlanyo Deffor*
}

University of Ghana Business School, Department of Organization and Human Resource Management Legon, Accra-Ghana West Africa

\begin{abstract}
Genetic Modification (GM) is a rapidly growing technology that can improve productivity and profitability for producers. The study assessed consumer acceptance of GM foods in the Greater Accra Region of Ghana. The study is based on a survey conducted in three districts of the Greater Accra Region namely, Accra Metropolitan Assembly (AMA), Ga East (GE) and Tema Metropolitan Assembly (TMA) using purposive sampling method. A qualitative choice (Logit) model was used to estimate the effect of various factors on consumer acceptance of GM foods. The results obtained showed that, about $90 \%$ of the respondents had heard or read something about GM foods indicating a high level awareness among respondents' in the Greater Accra Region. The results also show that $85 \%$ of the respondents were willing to accept GM foods. From the logit model, consumers with age groups $31-40$ and above 50 years, were more likely to accept GM foods in the study area where as male respondents were less likely to accept GMFs. In addition, respondents with secondary and tertiary levels of education were likely to accept GM foods. Household size 1 to 5 , reading product labels as well as understanding of science and technology were also significant variables in explaining consumer acceptance of GM foods in the Greater Accra Region. Obviously awareness and education was shown to be a necessary condition for acceptability of GM foods. The recommendation of this study is to promote effective education about the benefits of GM foods to increase the potential for acceptance.
\end{abstract}

Keywords: Genetically modified food; Consumer acceptance; Logit; Ghana

\section{Introduction}

Genetically Modified Foods (GMFs) are defined as plant and animal products obtained from a collection of scientific techniques that involve taking genes from one plant or animal species and inserting them in another species to transfer a desired trait or characteristic. Most often proponents of agricultural biotechnology view its application as the gate way to the future of food production. In other words, its application holds the potential of making available a wide variety of products with high nutritional, environmental, and economic benefits [1]. In fact the role of biotechnology in the future of agriculture and food production according to Hallman et al. [2] has become increasingly significant as billions of dollars has been and is being spent to develop new and improved foods, fuel, feeds, fibers, pharmaceuticals, and nutraceuticals. The benefits the technology holds for agricultural producers, is the potential of reducing production costs, enhanced yields, and also the potential for increased profits. Additionally, other potential benefits include reductions in pesticide and herbicide use, as well as the potential for enhanced nutritional value, flavor, and shelf life of some foods [3].

Despite these stated advantages, genetically modified foods (GMF) have received mixed regulatory and public acceptance even in the United States and elsewhere [2]. Also as more products developed through biotechnology reach store shelves, consumer reception continue to be mixed. This has been the case especially in Europe where adoption has been met with caution and in some cases rejected altogether as observed by [4,5]. Evidence from Kimenju et al. [6] study indicate that consumer organizations, environmentalists and other non-governmental organizations have expressed concerns about GM foods on the grounds of food safety, ethics, religion and the possible effect on the environment; in addition to the above stated concerns the lack of consumer choice due to inadequate labelling is also expressed. Basically, these concerns are mainly due to consumer perceptions and the fear of the unknown i.e. GMO's may pose some long-term unforeseen health risks, as well as the risk of negative effects on wildlife and the environment. These consumer perceptions are very critical if consumers will accept GM foods [7-9].

However, there is a lack of scientific data concerning environmental and health effects from both industrial and public research sources that consuming GM foods can lead to some unforeseen effect. Indeed, there is little evidence that eating today's GM foods is unhealthy, except in rare cases of allergenicity [10,11]. These assurances notwithstanding, consumer concerns are still high; therefore the application of GM technology to produce food can only be successful if consumers accept the end result. In other words, the future development of gene technology depends heavily on public acceptance. Indeed, public attitude toward genetic engineering and the subsequent acceptance of products derived from the technology is becoming increasingly important in determining the future role of the technology in society. If consumer acceptance issues are not adequately addressed, then the potential economic and social benefits of modern biotechnology may not be realized [12]. Clearly, consumers' acceptance of GM foods form a critical factor that will help determine its future, hence the need to establish the level of consumers' awareness, perceptions and concerns about GM foods and their readiness to accept and subsequently use them. This research therefore possess these questions: Is the policies available in Ghana regarding Biotechnology clearly known? What is the level of awareness of consumers in the Greater Accra Region? What

*Corresponding author: Eric Worlanyo Deffor, University of Ghana Business School, Department of Organization and Human Resource Management P.O. Box LG 78, Legon, Accra-Ghana West Africa, Tel: 233-20-455-5346; E-mail: ericdeffor@gmail.com

Received May 15, 2014; Accepted June 30, 2014; Published July 02, 2014

Citation: Deffor EW (2014) Consumer Acceptance of Genetically Modified Foods in the Greater Accra Region of Ghana. J Biosafety Health Educ 2: 116. doi:10.4172/2332-0893.1000116

Copyright: ( 2014 Deffor EW. This is an open-access article distributed under the terms of the Creative Commons Attribution License, which permits unrestricted use, distribution, and reproduction in any medium, provided the original author and source are credited. 
factors affect consumer acceptance of GM foods? What is the effect of these factors on consumer willingness to accept GM foods? This study attempts to provide answers to the questions raised.

A review by Costa-Font et al. [13] systematically summarized evidence on the acceptance of GM food and its underlying processes. The main issues captured by the study were risks and benefits perceptions, trust, knowledge, and valuation, as well as purchasing decisions. The study also identified three kinds of population that are studied in literature namely, anti-GM food or pessimistic, risktolerant or information searchers, and GM-accepters or optimistic and indicated that different compositions of such groups in a specific society determines final acceptance of GM food. The review also pointed out that most studies showed that consumers preferred GM free food until the point to pay premium for them. Preferences were analyzed with varying technics such as stated preferences, real markets, blind taste, etc. It also pointed out that consumer behavior can be related to the associated benefits, information, gender, age, knowledge and so on of GM food. Empirical evidence have also supported and further added different dimensions to the earlier studies. Even though consumers in Venezuela are adequately informed about microbial and pesticides contamination, they are highly misinformed about GM foods [14]. Another study in China revealed that information on GM foods is less available but awareness is high among urban consumers. Information and prices of GM foods were two important factors affecting consumers' attitudes toward GM foods. The study concluded that the commercialization of GM foods is not likely to receive great resistance from the consumers in China [15].

Unlike the two studies discussed in the paragraph above, Krualee and Napasintuwong [16] applied multinomial logit regression to examine the factors that affect the willingness of consumers in Thailand to pay for non-GM food labeling in Thailand. The results suggest that non-GM labeling is an appropriate policy for Thailand when the majority of consumers are averse to GM food and willing to pay less for GM contaminated products or if they consider negative health impacts a serious problem. Using experimental auction methodology, Huffman [17] assessed willingness to pay for food products that might be made from new transgenic and intragenic genetically modified (GM) traits among consumers. The study showed that the consumers respond to both food labels and information treatments, but no single type of information is dominant.

Acceptance of innovations or willingness to accept innovations have also been examined in the field of agriculture. Chebil et al. [18] analyzed the factors that affect farmers' willingness to adopt salt-tolerant forage for livestock, using a Tobit model. The study found positive relationship between willingness to adopt and off-farm income and flock size variable. Another study by Asante et al. [19] employed Probit regression to examine the willingness of farm households to adopt improved yam technologies. In addition to information obtained through extension, media and training, willingness to accept the technology was informed by socioeconomic, technical and individual attributes.

This study also applied a Logit regression procedure to assess consumer willingness to accept genetically modified food in the Greater Accra Region. Specifically, the study determined the level of consumer awareness about GM food in the study area and then modeled the effect of the factors that determines consumer acceptance of GM foods in the region.

\section{Methodology}

\section{The Logit framework}

This model has been used to estimate the effect of socioeconomic variables, sensory variables, and psychographic variables on consumer preferences for GM foods. The empirical model assumes that the consumer's probability to consume (acceptance) genetically modified food, $\mathrm{P}_{\mathrm{i}}$, depends on a vector of independent variables $\left(\mathrm{X}_{\mathrm{ik}}\right)$ associated with consumer $i$ and variable $j$, and a vector of unknown parameters $\beta$ [1]:

$$
P_{i}=F\left(Z_{i}\right)=F\left(\alpha+\beta X_{i}\right)=\frac{1}{\left[1+\exp \left(-Z_{i}\right)\right]}=\frac{1}{\left[1+\exp -\left(\alpha+\beta X_{i}\right)\right]}
$$

where denotes $F\left(Z_{i}\right)$ denotes the value of logistic cumulative density function associated with each possible value of the underlying $Z_{i} ; P_{i}$ denotes the probability that an individual would consume the specific $\mathrm{GM}$ food product, given the independent variables $\mathrm{X}_{\mathrm{i}}$.

To estimate the model above, multiply both sides of equation (1) by to get:

$$
\left[1+\exp \left(-Z_{i}\right)\right] P_{i}=1
$$

By dividing by $\mathrm{P}_{\mathrm{i}}$, and then subtracting 1 leads to

$$
\exp \left(-Z_{i}\right)=\frac{1}{P_{i}}-1=\frac{1-P_{i}}{P_{i}}
$$

By definition, however,

$$
\exp \left(-Z_{i}\right)=\frac{1}{\exp \left(-Z_{i}\right)}
$$

So that

$$
\exp \left(-Z_{i}\right)=\frac{P_{i}}{1-P_{i}}
$$

and by taking the natural logarithm of both sides, we obtain

$$
Z_{i}=\log \frac{1}{1-P_{i}} \quad \text { or } \quad \log \left[\frac{P_{i}}{1-P_{i}}\right]=Z_{i}=\alpha+\beta X_{i}
$$

The dependent variable in the regression equation above is the logarithm of the odds that a particular choice will be made.

In the above equation, is a linear combination of the independent variables so that

$$
Z_{i}=\log \left[\frac{P_{i}}{1-P_{i}}\right]=\beta_{0}+\beta_{1} x_{i 1}+\beta_{2} x_{i 2}+\beta_{3} x_{i 3}+\ldots . . \beta_{k} x_{i k}+\varepsilon_{i} \quad i=1,2,3 \ldots ., n
$$

where $Z_{i}$ denotes unobserved index level or the log odds of choice for the $\mathrm{i}^{\text {th }}$ observation; $\mathrm{X}_{\text {ik }}$ denotes $\mathrm{k}^{\text {th }}$ attribute of the $\mathrm{i}^{\text {th }}$ respondent; $i$ denotes observation; $\beta$ denotes parameters to be estimated; $\varepsilon$ denotes random error or disturbance term. The dependent variable $Z_{i}$ in equation (5) is the logarithm of the probability that a particular choice will be made. The maximum likelihood method of estimation was employed to estimate the logit model, since the individual Pi are not observed; rather the measured dependent variable was $\mathrm{y}_{\mathrm{i}}=1$ the choice is made and zero (0) otherwise are. The estimated parameters of equation (5) do not directly represent the marginal effects of the independent variables on $P_{i}$. For a continuous variable, the marginal effect of $x_{k}$ on the probability $P_{i}$ that the dependent variable $(y)$ takes the value $y_{i}=1$ is given by:

$$
\frac{\partial P_{i}}{\partial x_{i j}}=\frac{\left[\beta_{j} \exp \left(-\beta X_{i}\right)\right]}{\left[1+\exp \left(-\beta X_{i}\right)\right]^{2}}
$$

However, if the independent variables are also qualitative or discrete in nature, as is the case for the independent variables used in this study, the marginal effect of a discrete independent variable is obtained by evaluating $\mathrm{P}_{i}$ at alternative values of $\mathrm{x}_{i j}$. Marginal effects of such variables are determined as: 
Citation: Deffor EW (2014) Consumer Acceptance of Genetically Modified Foods in the Greater Accra Region of Ghana. J Biosafety Health Educ 2: 116. doi: $10.4172 / 2332-0893.1000116$

Page 3 of 6

\begin{tabular}{|c|c|c|}
\hline & Characteristics & \\
\hline Gender & Frequency & Percent \\
\hline Male & 155 & 64.6 \\
\hline Female & 85 & 35.4 \\
\hline Total & 240 & 100 \\
\hline Age & & \\
\hline $20-30$ & 157 & 65.4 \\
\hline $31-41$ & 46 & 19.2 \\
\hline $41-50$ & 21 & 8.8 \\
\hline Above 50 & 16 & 6.7 \\
\hline Total & 240 & 100 \\
\hline & Household size & \\
\hline 41644 & 80 & 33.3 \\
\hline 41800 & 123 & 51.3 \\
\hline 41958 & 37 & 15.4 \\
\hline Total & 240 & 100 \\
\hline
\end{tabular}

Table 1: Distribution of Respondents According To Socio-Economic Characteristics.

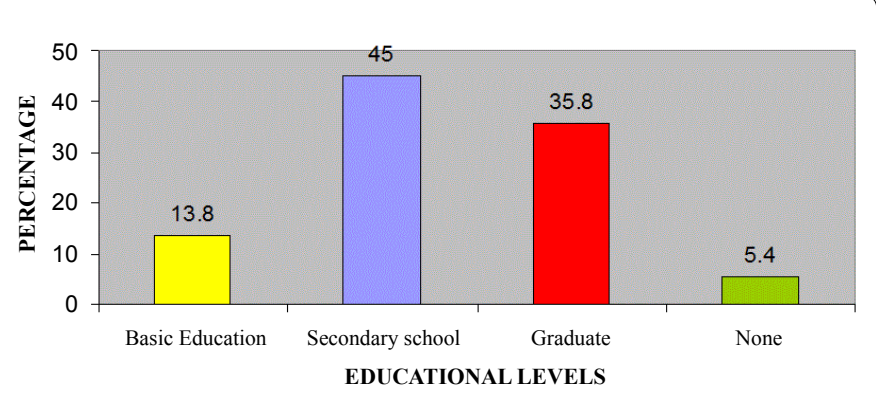

Figure 1: Distribution of respondents according to educational level.

$$
\frac{\partial P_{i}}{\partial X}=\beta_{i}\left[P_{i}\left(1-P_{i}\right)\right]
$$

To obtain the marginal effect or response, we take the means of all the explanatory variables and multiply each mean by its estimated parameter to obtain Pi. The maximum likelihood method of estimation was employed to estimate the logit model.

\section{Empirical Logit Model}

In the empirical analysis, the following model is used to predict the probability or the log odds that an individual consumer will consume or accept GM food product:

$$
\begin{gathered}
\text { WACCEPT }=\beta_{0}+\beta_{1} P R I C+\beta_{2} \text { SEX }(M A L E)+\beta_{3} A G E 31_{-} 40+\beta_{4} A G E 41_{-} 50+\beta_{5} A G E_{-} A B 50 \\
+\beta_{6} \text { EDUC2 }+\beta_{7} E D U C 3+\beta_{8} E D U C 4+\beta_{9} H H S I Z E 15+\beta_{10} H H S I Z E 610 \\
+\beta_{11} H E A R D+\beta_{12} R E A D L+\beta_{13} R E L C O N+\beta_{14} S A F C O N \\
+\beta_{15} \text { ETHICONC }+\beta_{16} U N D S C_{-} T E C+\beta_{17} R E G U L+\varepsilon
\end{gathered}
$$

\section{Statement of hypotheses}

The following hypotheses were tested for equation (1) based on apriori expectations:

1. H0: Price has no effect on the willingness to accept GM foods

H1: Price has a negative effect on the willingness to accept GM foods

This hypothesis is also tested for the following variables: Age, and Ethical concerns, safety concerns and religious concerns.

2. H0: Level of education has no effect on the willingness to accept GM foods
H1: Level of education has a positive effect on the willingness to accept GM foods

3. H0: Government control has no effect on the willingness to accept GM foods

H1: Government control has a positive effect on the willingness to accept GM foods

4. H0: Sex has no effect on the willingness to accept GM foods

H1: Sex has a positive or negative effect on the willingness to accept GM foods

This is repeated for the following variables: Reading of labels, Awareness (knowledge about GM), Household size.

\section{Validation of hypothesis}

The $\mathrm{Z}$ statistic is used to measure the level of significance for each of the estimated coefficients. If $Z$ calculated is greater than the $Z$ critical the null hypothesis is rejected in favors of alternate. Also, the goodness of fit statistic given is the Mc-Fadden R-square. The likelihood ratio (LR) test is computed to determine the joint significance of the independent variables in the model. The LR test statistics follows the chi-square $\left(\chi^{2}\right)$ distribution with the degrees of freedom equal to the number of independent variables used in the model. The higher the percentage of prediction the greater the predictive power of the model.

\section{Data collection method}

Purposive sampling technique was used to select respondent from three Municipal/District Assemblies in the Greater Accra Region of Ghana, namely the Accra Metropolitan Assembly (A.M.A), the Ga East and Tema Municipal Assembly (T.M.A) with some level of education. The choice was largely influenced by the technical nature of the research topic; hence some level of education on the part of the respondents was needed to facilitate easy explanations and questionnaire administration. However, some data was collected on respondents who had little or no formal education, notwithstanding the difficulty encountered in explaining the terminologies to them.

\section{Results and Discussion}

\section{Demographic characteristics of respondents}

From Table 1, male respondents formed the largest proportion of respondents having a frequency of 155 representing $65 \%$ of the total respondents; with 85 (35\%) being females. In the age category $65 \%$ of the respondents were within the age group 20-30; followed by $19 \%$ within the age group 31-40; with $7 \%$ belonging to the age group 50 years and above. The results presented generally indicate that most of the respondents interviewed were relatively young or in their youthful age. The household sizes of the respondents were grouped into 1-5, 6-10 and 11-15. Majority (123) of the respondents had household sizes within 6-10 representing 51\%; the least household size group was 11-15 having a percentage of 15 . The result is indicative of the fact that most of the respondents have large family sizes. See Table 1 for details. The educational levels of respondents are shown by Figure 1; majority of them had attained some level of formal education ranging from basic to tertiary levels of education. 108 of the respondents had attained secondary (SSS; O/A Level) level of education representing $45 \%$; whereas $36 \%$ of them had tertiary level of education. Only a small number $(5 \%)$ of the respondents indicated they had no form of formal education. Most of the respondents were educated because the respondents were purposively sampled. 


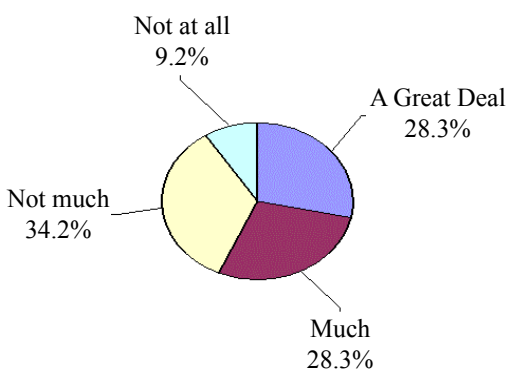

Figure 2: How much have you heard or read about GM foods.

\begin{tabular}{|c|c|c|}
\hline Response & Frequency & Percent \\
\hline Yes & 204 & 85 \\
\hline No & 36 & 15 \\
\hline Total & 240 & 100 \\
\hline
\end{tabular}

Table 2: Willingness to accept $\mathrm{GM}$ foods if their production and importation is regulated by a Government Agency (FDB, SD, AEC).

\begin{tabular}{|c|c|c|c|}
\hline Variables & Coefficients & Marginal Effect & Probability \\
\hline MALE & -0.59 & -0.143 & $0.0856^{*}$ \\
\hline AGE3140 & -1.174 & -0.284 & $0.0039^{* * *}$ \\
\hline AGE4150 & 0.842 & -- & 0.1813 \\
\hline AGEABV50 & -1.828 & -0.442 & $0.0046^{* * *}$ \\
\hline EDUC2 & 0.866 & -- & 0.2926 \\
\hline EDUC3 & 1.281 & 0.31 & $0.0766^{\star * *}$ \\
\hline EDUC4 & 1.196 & 0.289 & $0.1026^{*}$ \\
\hline HHSIZE15 & 0.779 & 0.188 & $0.0777^{*}$ \\
\hline HHSIZE610 & -0.143 & -- & 0.7238 \\
\hline PRICE & 0.052 & -- & 0.8687 \\
\hline HEARD & 0.026 & -- & 0.9367 \\
\hline UNDSC_TEC & 0.725 & 0.175 & $0.0496^{\star *}$ \\
\hline READL & 0.614 & 0.148 & $0.0653^{\star *}$ \\
\hline ETHICGM & 0.447 & -- & 0.1991 \\
\hline SAFECON & 0.193 & -- & 0.5731 \\
\hline RELCON & -0.62 & -0.15 & $0.1047^{*}$ \\
\hline REGUL & 0.985 & 0.238 & $0.0019^{\star * *}$ \\
\hline $\mathrm{C}$ & -1.874 & -0.453 & 0.0408 \\
\hline Mean dependent var & 0.591667 & S.D. dependent var & 0.492553 \\
\hline LR statistic (17 df) & 58.25616 & McFadden R-squared & 0.179472 \\
\hline Probability (LR stat) & 0.00000203 & & \\
\hline
\end{tabular}

Table 3: Logit Results, Dependent Variable: WACCEPT, Method: ML-Binary Logit * Indicates statistically significant at the $10 \%$ level; **Indicates statistically significant at the $5 \%$ level; ${ }^{* * *}$ Indicates statistically significant at the $1 \%$ level

\section{Consumer awareness of genetically modified foods}

To find out whether consumers were aware of genetically modified foods, the question how much have you heard or read about Genetically Modified Foods was asked respondents. Out of the total, 240 respondents $34 \%$ said they had not heard much about genetically modified foods; $28 \%$ a great deal; with less than $10 \%$ indicating they had not heard or read anything about genetically modified foods. Generally, most respondents had some basic knowledge (i.e. read or heard) of GM foods, this significant level of awareness is attributable to recent issues on genetically modified foods in the media regarding some alleged contamination of some imported rice with unapproved strain of genetically modified rice in the country (i.e. during the period of data collection) as well as the fact that more educated respondents were sampled hence might have read or heard about genetically modified foods on their own (Figure 2).
Boccaletti and Moro [4] demonstrated that consumer trust in companies and scientists conducting research in the area of gene technologies has a strong effect on perception of risks and benefits associated with those technologies. Therefore if a consumer's level of trust in regulatory bodies is high the likelihood that that consumer will be willing to accept GM foods will be high. The question was asked in the questionnaire; Will you accept GM Foods if their production and Importation is regulated and certified by a Government Agency such as (FDB, SD, AEC). In other words, Do consumers trust (FDB, $\mathrm{SD}$, and $\mathrm{AEC}$ ) to regulate the importation and productions of GM foods in Ghana? The result as presented in Table 2 show that generally majority of the respondents (85\%) indicated they will accept genetically modified foods if their production or importation was regulated by these government agencies such as Ghana Atomic Energy Commission (GAEC), Food and Drugs Board (FDB), and Standard Board (SD). Indicating that most of the respondents have a high level of trust in these government agencies to ensure the safety of the foods and drugs they consume likewise GM foods (Table 2). This result is probably in line with the statement that consumers in developing countries are most likely to have high trust in government agencies to regulate the importation and production of GM foods [20].

\section{Factors affecting consumer's acceptance of genetically modified foods}

Most (59\%) of the respondents expressed their willingness to accept genetically modified foods if they were introduced into the country. Only $40.2 \%$ were not ready to accept genetically modified foods. This result indicates a slightly above average level of consumer acceptance of genetically modified foods in the study area, although they expressed some reservations. The Logit model was employed to investigate the effect of some identified factors on consumer acceptance of GMFs. The results in Table 3 shows that the age variables AGE3140 and AGEABV50, trust in regulatory agencies (REGUL) and secondary level of education (EDUC3) were significant at $1 \%$ level of significance, followed by reading of labels (READL) and understanding of science and technology (UNDSC_TEC) been significant at 5\% level of significance. Other variables such as Religious Concern (RELCON), Household size of 1-5 (HH15), gender (MALE) and tertiary level of education (EDUC4) was significant at $10 \%$ level of significance. The marginal effects, which represent the probability of accepting Genetically Modified foods, were calculated for each significant variable. AGE3140 and AGEABV50 years were significant and meet the apriori expectation. The findings show that the all things being equal, the probability that a consumers or respondents in these age groups accepting GM foods will decrease by -0.284 , and -0.442 likelihood respectively in the study area. Secondary school level (EDUC3) of education was also found to be significant with a positive sign meeting the a priori expectation.

The implication is that respondents with at least secondary level of education are likely to accept GM foods in the study area will as well as respondents with tertiary level of education even though their levels of significance vary. The educational variables were also found to have met the apriori expectation of a positive sign. This findings support the assertion that education provides an individual/consumer with the ability to seek, evaluate and understand information about innovation which invariably can influence their likelihood to accept innovations in this context GM foods ceteris paribus. Further analysis of the model results showed that Household size (HHSIZE15) was significant with a positive sign meeting the apriori expectation, indicating the probability or likelihood of a respondent with household size of 1 to 5 accepting GM foods in the study. As households size increases the tendency to be 
exposed to innovation and information becomes high since members are likely to join the society for their daily activities and are exposed to information about the possible usefulness or benefits of GM foods and can easily fall into the state of acceptability.

The findings also indicate that male respondents had a -0.14 likelihood of accepting GM foods in the study area. The findings imply that male respondents in households are less likely to take the risk of accepting or by extension purchasing GM foods. It important to indicate that some studies have shown that females are more willing to try innovation nonetheless the decision, of application of innovation has been noted to increases with for males may be due to their access to economic resources [19]. Another key determinant of GM acceptance in the study area is labeling; this was found to be significant in the model with a positive sign; meaning that there is the likelihood of a consumer who reads food labels will accept GM foods; perhaps due to that fact that product labels always portray the benefits of products have the tendency to shape the perception of consumers.

From the model concerns expressed on the grounds of religion was significant with a negative sign. Implying that there is the likelihood for a consumer who express reservations about GM foods based on their religious beliefs not to accept GM foods; this perhaps might be fueled by the perception that GM food production process contradict religious beliefs and teachings. Also, the variable UNDSC_TEC was significant meeting the positive apriori expectation. The result means that ceteris paribus, the likelihood that a consumer with some basic understanding of science and technology accepting GM foods will increase by 0.175 and vice versa. Understanding of science eliminates any fear about the possible hazards of GM foods and this may have contributed to positive relationship. Consumer trust in regulatory bodies was highly significant in the model, meaning that the likelihood of a respondents accepting GM foods if the regulations was certified by these government will increase by 0.24 units confirming reports [6] that higher trust in regulatory mechanisms leads to lower resistance to genetic and biotechnology products.

\section{Conclusion}

The conclusion of this study is based on respondents purposively selected from the main districts of in the capital city of Ghana Accra. A Logit model was used to assess the effect of some selected variables on the acceptance of GM foods in the study area. Primarily the issue of acceptance of GM foods and its subsequent use in developing countries such as Ghana is perhaps a critical policy decision to make by government and the relevant regulatory authorities. However, this decision cannot be made without recourse to the end user i.e. consumer. It is important therefore that policy decision in this regard takes into consideration the perceptions and acceptance of consumers based on sound research findings. The study therefore concludes that awareness about benefits or otherwise of GM foods is critical to acceptance of GM foods in the study area especially among individuals with some level of education. Trust and confidence in regulatory institutions on the part of consumers can influence the acceptance of GM foods in the study area; it is important therefore for these organizations to position themselves to allay the fears and concerns of consumers regarding GM foods. Again there would be a need to for proper labeling of GM foods for consumers in the study area to make informed choice during purchase of the groceries etc.

\section{Policy Recommendations}

The analysis contributes to a better understanding of the factors influencing consumer acceptance of GM foods in the study area. Therefore before the introduction of GM foods into the country it will be reassuring to consumers if concerns relating to health, safety, and the environment are taken into consideration. It is therefore suggested that policy makers should focus their educational efforts aimed at convincing consumers to accept genetically modified foods through recommended electronic and the print media (i.e. both local and international) should be channels through which to educate consumers to allay them of the concerns and reservations they have towards GM foods. Also policy makers must consider strongly the issues of labeling of GM foods to distinguish it from other food products for consumers to make their choice.

\section{References}

1. Hossain F, Adelaja A Brian H, Onyango B, Schilling W (2002) "Consume Acceptance of Food Biotechnology: Willingness to Buy Genetically Modified Food Products." New Jersey: Food Policy Institute, Rutgers University.

2. Hallman WK, Adelaja AO, Schilling BJ, Lang J (2002). Public Perceptions of Genetically Modified Foods: Americans Know Not What They Eat. Publication No. RR-0302-001, Food Policy Institute, Rutgers University

3. Harrison RW, Jae-Hwan Han (2004) The Effects of Risk Perceptions on United States Consumer Preferences for GMO Labelling Paper presented at the 14th International Food and Agribusiness Management Association Annual World Food and Agribusiness Symposium and Forum, June 12-15, 2004.

4. Boccaletti S, Moro D (2000) Consumer Willingness-To-Pay for Gm Food Products in Italy. AgBioForum 3: 259-267.

5. Burton M, Rigby D, Young T, James S (2001) Consumer Attitudes to Genetically Modified Organisms in Food in the UK. European Review of Agricultural Economics 28(2001): 479-493.

6. Kimenju SC, De Groote H, Karugia J, Mbogoh S, Poland D (2004) Consume Awareness and Attitudes toward GM foods in Kenya. International Maize and Wheat Improvement Centre (CIMMYT) Nairobi, Kenya IRMA Socioeconomics Working Paper 2004-01.

7. Hoban TJ (1998) Trends in Consumer Attitude about Agricultural Biotechnology AgBioForum 1.

8. Caulder J (2001) "Agricultural Biotechnology and Public Perceptions," Agbio Forum.

9. Hallman WK Metcalfe J (2001). "Public Perceptions of Agricultural Biotechnology: A Survey of New Jersey Residents".

10. Domingo JL (2000) Health risks of GM foods: many opinions but few data Science 288: 1748-1749.

11. Wolfenbarger LL, Phifer PR (2000) The ecological risks and benefits of genetically engineered plants. Science 290: 2088-2093.

12. Stenholm CW, Waggoner DB (1992) Public policy, in animal biotechnology in the 1990s: challenges and opportunities, in MacDonald JF (Eds) Animal biotechnology: Opportunities and Challenges, National Agricultural Biotechnology Council, Ithaca, New York, NY, 25-35

13. Costa-Font M, Gil JM, Traill WB (2008) Consumer acceptance, valuation of and attitudes towards genetically modified food: Review and implications for food policy. Food Policy 33: 99-111.

14. Pereira de Abreu DA, Rodriguez KV, Schroeder M, de Mosqueda MB, Pérez E (2006) GMO Technology. Venezuelans' Consumers Perceptions: Situation In Caracas. Journal of Technology and Management Innovation 1: 80-86.

15. Huang J, Quu H, Bai J, Pray C (2006) Awareness, acceptance of and willingness to buy genetically modified foods in Urban China. Appetite 46: 144-151.

16. Krualee S, Napasintuwong $O$ (2012) Consumers' willingness to pay for non-gm food labeling in Thailand. International Food Research Journal 19: 1375-1382.

17. Huffman WE (2010) Consumer Acceptance of Genetically Modified Foods: Traits, Labels and Diverse Information. Working Paper No. 10029. lowa State University, Department of Economics. August 2010.

18. Chebil A, Nasr H, Zaibet $L$ (2009) Factors affecting farmers' willingness to adopt salt-tolerant forage crops in south-eastern Tunisia. Afjare 3: 19-27. 
Citation: Deffor EW (2014) Consumer Acceptance of Genetically Modified Foods in the Greater Accra Region of Ghana. J Biosafety Health Educ 2: 116. doi: $10.4172 / 2332-0893.1000116$

Page 6 of 6

19. Asante BO, Otoo E, Wiredu AN, Acheampong P, Osei-Adu J, et al. (2011) Willingness to adopt the vine multiplication technique in seed yam production in the forest savanna transition agro-ecological zone, Ghana. Journal of Development and Agricultural Economics 3: 710-719.
20. McFadden D (2001) Economic Choices. American Economic Review 91: 351 378. 